\title{
Research on green credit risk measurement based on Pair Copula grouping model--From the perspective of Commercial Banks
}

\author{
Han Sun, Hui-zi $\mathrm{Ma}^{*}$, and Xiang-rong Wang \\ Shandong University of Science and Technology, Institute of Financial Engineering, Qingdao 266590, China
}

\begin{abstract}
In order to measure the portfolio credit risk of commercial banks in energy saving and environmental protection industry accurately, this paper proposes the value $\mathrm{VaR}_{\mathrm{GP}}$ of green credit risk and constructs a related model based on Pair Copula grouping model,VaR method (combined with enumeration algorithm). The results show that the credit schemes that commercial banks focus on investing in two areas of industrial emission reduction and environmental restoration is consistent with the conclusion that the two fields have the strongest development momentum.Besides, at different levels of confidence, all of VaR $\mathrm{RP}_{\mathrm{GP}}$ have passed the return test, which fully shows that the model is feasible and effective to measure the credit risk in different green fields and to formulate the optimal combination strategy.
\end{abstract}

\section{Introduction}

In recent years, environmental pollution, resource depletion and other global environmental problems are increasingly prominent. To be helpful for the economy and the nature coordinated sustainable development, environmental protection administration, the people's bank of China and the China banking regulatory commission have proposed "green credit", which aims to promote the transformation of enterprises to energy conservation, emission reduction and environmental protection through financial leverage.In the field of financial market, portfolio method [1]is often used to reduce investment risk. This paper regards green credit behavior as an investment behavior of commercial Banks. Therefore, how to describe the dependency structure among green environmental protection Ipractical significance for Banks to enhance their ability to control risks and make correct credit decisions.

On measuring the risk of green credit, Wang et al. (2011)[2]proposed the system of testing the green credit scoring and risk assessment SVM model about support vector machine.Based on the KMV model proposed by Zhihong Mo et al. (2015)[3], Youhui Li (2018)[4] predicted the credit risk of listed companies in the paper industry from two aspects of finance and green development by combining BP neural network. However, green credit risk is caused by environmental risk, credit risk, operational risk, legal risk, market risk and other factors[5], at the same time, various risk factors are difficult to quantify. Therefore, the above risk measurement method cannot be fully applied to the green credit risk assessment of commercial Banks.

The Copula function proposed by Sklar (1959) [6]is often used to describe the complex dependency structure among multiple variables in the financial market to measure the risk of investment portfolio. But so far, traditional Copula method and vine Copula are all studies on the same type of dependence, which fails to take into account the different characteristics of interdependence among different financial industries. Zhenlong Chen et al. (2018) [7], on the basis of the binary Copula grouping model proposed by Zhou (2016) [8], proposed the model combining the vine Copula grouping and Mean-ES to optimize the risks of investment banking, securities industry and insurance industry.

In order to simplify the calculation steps, we combined pair Copula group with value-at-risk VaR that introduces enumeration algorithm in this paper, apply it in the field of evaluating green credit risk and optimizing lending weight, and use return test to verify the feasibility and accuracy of the model.This provides basis for measuring the risk of green credit and making high-dimensional green loan portfolio decisions for commercial Banks.

\section{Establishment of Model}

\subsection{Vine structure}

The pair Copula proposed by Bedford and Cooke $(2001,2002)$ [9] is used to characterize the dependent structures among variables. The proposed vine structure overcomes the limitations of traditional Copula that can not accurately measure the different dependent structures among different variables. The vine structure divides variables into a large number of binary structures, according to the specific characteristics between the two

\footnotetext{
*Corresponding author: Hui-zi Ma e-mail: 1339632077@qq.com
} 
variables choose the appropriate Copula function to establish a joint distribution.

The joint density function of D-vine structure is:

$$
\begin{aligned}
f\left(x_{1}, x_{2}, x_{3}\right)= & f\left(x_{1}\right) f\left(x_{2}\right) f\left(x_{3}\right) \\
& c_{12}\left(( F ( x _ { 1 } ) , F ( x _ { 2 } ) ) c _ { 2 3 } \left(\left(F\left(x_{1}\right), F\left(x_{3}\right)\right)\right.\right. \\
& c_{13 \mid 2}\left(F\left(x_{1 \mid 2}\right), F\left(x_{3 \mid 2}\right)\right)
\end{aligned}
$$

The joint density function is the product of the Copula density function and the edge density function of each vine structure. In this paper, $\mathrm{R}$ vine without any fixed structural characteristics is adopted, which describes the dependency structure between complex variables only according to the real correlation between variables, so it is more flexible and accurate.

\subsection{Pair Copula grouping model}

Based on the ideas of Zhou et al. and Zhenlong Chen et al.,this paper divides the green environmental protection enterprises into groups according to their business fields. Firstly, Pair Copula is used to describe the relationship of dependence between logarithmic returns of listed green environmental protection enterprises in each group, so as to obtain the optimal loan portfolio with the lowest VaR. Then, the return rate of stocks in each group is weighted and summed to obtain the return rate sequence of stocks among groups used to describe each field. Next, the sub-and return sequence between the above groups are taken as new research variables.Pair Copula is still used to describe the dependency relationship between yields of each group.

The Pair Copula grouping model based on the object studied in this paper is as follows:

$$
X\left(V C_{X}\right)\left\{\begin{array}{c}
X_{1}\left(V C_{X_{1}}\right)\left\{\begin{array}{c}
X_{1,1}\left(F_{11}\right) \\
\vdots \\
X_{1,8}\left(F_{18}\right)
\end{array}\right. \\
\vdots \\
X_{6}\left(V C_{X_{6}}\right)\left\{\begin{array}{c}
X_{6,1}\left(F_{61}\right) \\
\vdots \\
X_{6,7}\left(F_{66}\right)
\end{array}\right.
\end{array}\right.
$$

Among them, $V C_{X}$ represents the vine structure of vector $\left\{X_{1}, X_{2}, \ldots, X_{6}\right\}$ between groups, $V C_{X_{i}}$ represents the vine structure of the vectors in each group. $\left(X_{i, 1}, X_{i, 2}, \ldots, X_{i, j}\right)$ are green enterprises in the same industry.

\subsection{VaR based on enumeration algorithm}

Combined with enumeration algorithm, generate the weight combination of 1000 groups that add up to 1 . Through $s_{j}=\sum_{i=1}^{6} \omega_{i}\left(x_{i, t}^{\prime}\right)_{j}, j=1,2, \ldots, N$, it can be obtained that the number of $\mathrm{N}$ predicted values of the return sequence of the green environmental protection enterprises in each business field on $\mathrm{t}$ day, and write for $\left\{s_{1}, s_{2}, \ldots, s_{N}\right\}$. Then we're going to sort the predictions from largest to smallest. From the definition of $\mathrm{VaR}$, we can get: $\operatorname{VaR}_{\alpha}(s)=s^{(N \cdot \alpha+1)}$. So for confidence level $(1-\alpha)$, the absolute value of the number $(N \times \alpha)+1$ is the value of $V a R_{\alpha}$.

\section{The empirical analysis}

\subsection{Data preprocessing}

This paper evaluates the green credit risk of commercial Banks from the perspective of the daily return rate of listed companies listed in "green and environmental protection".The modeling object is the daily closing price of the stocks of 35 listed enterprises listed in the ranking list of China's listed environmental protection industry segments from 2015 to 2017 (hereinafter referred to as the ranking list). They roughly divided into six categories according to their business fields:

1).Industrial energy conservation and emission reduction $\mathrm{X}_{1}$ :(Triple environmental protection, Shenwu Environmental Technology, Kingland Technology, Kai Di Ecological, Green Eco-Manufacture, Shenwu Energy Saving, Beijing Shouhang Resources Saving Co.,Ltd.).

2).solid waste treatment $X_{2}$ : (Tus-sound Environmental Resources, Grand blue Environment, Dongjiang Envir-onmental Company Limited, Nanfang Pump Industry, Anhui Shengyun Environment Protection Group Co.,Ltd.).

3).Environmental restoration $X_{3}$ : (Beijing Orient Land-scape, Shenzhen Techand Ecology \& Environment, Inner Mongolia M-grass Ecology And Enviroment (Group), Shandong Meichen Science \& Technology Co.,Ltd.)

4).water treatment $\mathrm{X}_{4}$ :(About News Global Business Investor Relations Responsibility Join, Zhongshan Public Utilities Group, Chengdu Xingrong Environment, Beijing Capital,Tianjin Capital Environmental Protection Group, Kangda Environmental Protection Water Co.,Ltd.).

5).Atmospheric control $\mathrm{X}_{5}$ : (Fujian Longking,Yonker Environmental Protection, Spic Yuanda Environmental-Protection, CECEP Evironmental Protection Equipment, Zhejiang Feida Environmental Science\&Technology, Xuzhou Kerong Environmental Resources, Guodian Technology\&Environmental Group Co.,Ltd.) .

6).Environmental monitoring $\mathrm{X}_{6 \text { : }}$ (Infore Environment Technology Group, Centre Testing International Group ,HK HI-WELL TECH LIMITED, Hebei Sailhero Environmental Protection High-tech, Ningbo Ligong Environment And Energy Technology, Skyray instrument Co.,Ltd.).

The above 35 listed enterprises were selected from the sample data of solstice's daily closing price on October 22, 2018 on January 2, 2014, to reflect the profitability of each listed enterprise.The better an enterprise's profitability is, the better its loan repayment ability is, and the lower the default probability is, the less the green credit risk commercial Banks bear.

In this paper, abnormal data are eliminated, and each listed enterprise gets 1,170 observation values, a total of 40,950 data samples. 
According to $r_{i, t}=\ln P_{i, t}-\ln P_{i, t-1}$, we get the daily logarithmic return rate of each "green" listed company, where $P_{i, t}$ represents the daily closing price of stock $i$.The data came from the Choices database.

By weighting the logarithmic rate of return of the green companies in the group, we can obtain a logarithmic rate of return series describing the relationship among the six industries, and its descriptive statistical analysis is as follows:The logarithmic rate of return series between the six groups has the characteristics of peak tail characteristics, non-normal and wave aggregation, and their mean is almost 0 . In addition, augmented dickey-fuller (ADF) test showed that the logarithmic rate of return series was stable in the same order.

\subsection{The estimation of Copula grouping model and risk optimal}

The logarithmic rate of return sequence among 6 groups was obtained by adding the return sequences in the group according to the weights obtained, which can accurately and effectively depict the relationship of rate of return between 6 industries. Once again, the green credit risk measurement model based on Pair copula$\mathrm{VaR}$ is used to estimate the correlation coefficient matrix.

Then, pair-copula is used to obtain the dependence parameters of $\mathrm{R}$ vine structure among industries as follows:

Table 1. R - rattan structure and Copula function

\begin{tabular}{|c|c|c|}
\hline & $\mathrm{X}_{5}$ & $\mathrm{X}_{6}$ \\
\hline $\mathrm{X}_{1}$ & & $\mathrm{t}(0.5753,2.9374)$ \\
\hline $\mathrm{X}_{2}$ & $\mathrm{t}(0.6652,2.7655)$ & $\mathrm{t}(0.6406,3.3218)$ \\
\hline $\mathrm{X}_{3}$ & $\mathrm{t}(0.6050,3.5881)$ & $\mathrm{t}(0.6284,3.9293)$ \\
\hline $\mathrm{X}_{4}$ & $\mathrm{t}(0.5528,2.8386)$ & \\
\hline $\mathrm{X}_{5}$ & & $\mathrm{t}(0.7175,2.4208)$ \\
\hline
\end{tabular}

Note :() are the dependent parameters and degrees of freedom of t Copula

The structure of $\mathrm{R}$ vine is:

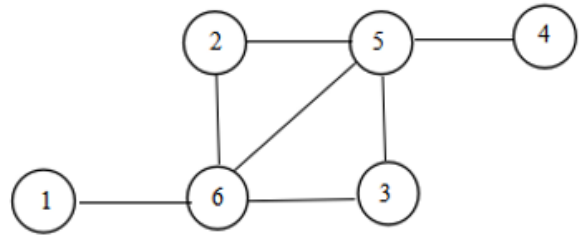

Figure 1. the structure of $\mathrm{R}$ vine in this group

$1,2, \ldots, 6$ respectively represents inter-group variable $X_{1}, X_{2}, \ldots, X_{6}$. The structure shows that Atmospheric control and Environmental monitoring in the six industries, are the key nodes in the six dependent relationships,and there is a tail dependent relationship.

The specific performance of this structure is as follows:The Copula function describing the dependency relationship between the stocks of atmospheric control class and the other four industry stocks is the t Copula function. At the same time, it also indicates that the environmental monitoring category has the greatest correlation with the tail of other industries, that is, the fluctuation of such returns has the greatest impact on other industries, followed by the atmospheric control category.

According to the dependent structure of the return sequence between different industries,using monte carlo simulations to generate 1000 random variables and 1000 weight combinations that add up to 1 ,we get the weight combination when the confidence level is $95 \%$ and $V a R_{G P}$ is the smallest.The result as shown in the following table:

Table 2. Optimal lending weight combination and the value of green credit risk

\begin{tabular}{|c|c|c|c|c|c|c|c|}
\hline$\alpha$ & \multicolumn{5}{|c|}{ optimal weight } & VaR $_{G P_{3}}$ \\
\hline $\begin{array}{c}95 \\
\%\end{array}$ & $\mathrm{X}_{1}$ & $\mathrm{X}_{2}$ & $\mathrm{X}_{3}$ & $\mathrm{X}_{4}$ & $\mathrm{X}_{5}$ & $\mathrm{X}_{6}$ & 0.0599 \\
\cline { 2 - 7 } & 0.4171 & 0.1104 & 0.4029 & 0.0076 & 0.0243 & 0.0377 & \\
\hline
\end{tabular}

From the above table, we can see that industrial emission reduction and environmental rehabilitation have the largest weight in the optimal loan portfolio. That is to say, environmental remediation and industrial energy conservation and emission reduction contribute the most to the return rate of the optimal credit portfolio, followed by solid waste treatment, which is consistent with the fact that the growth rate of net profit in these two fields is significantly higher than that in other fields in the report in 2017. According to the report, environmental remediation and industrial energy conservation performed well in sub-sectors,their revenue growth and net profit growth in these two areas are significantly higher than other areas.

Through comparison with the analysis results in the report,it is shown that the optimal credit weight calculated by the model in this paper with the lowest risk is consistent with the development trend of the industry in the past.It indicates that the model is feasible and effective, and commercial Banks can use this method to make the best decision according to the field of enterprises applying for green credit.

\subsection{Returns test}

We use the likelihood ratio (LR) test method based on VaR failure rate proposed by Kupiec to conduct 100 return tests on the green credit risks predicted based on Pair Copula grouping model, and the results of return test obtained are shown in the following table:

Table 3. The results of return test

\begin{tabular}{|c|c|c|}
\hline & \multicolumn{2}{|c|}{ VaR } \\
\hline Confidence level & $90 \%$ & $95 \%$ \\
\hline Minimum VaR $_{\mathrm{GP}}$ & 0.0394 & 0.0599 \\
\hline Pass times in return test & 89 & 96 \\
\hline P values & $0.180(\mathrm{~h}=0)$ & $0.5612(\mathrm{~h}=0)$ \\
\hline
\end{tabular}

Note: the null hypothesis is accepted when $\mathrm{h}=0$ and rejected when $\mathrm{h}=1$

The returned test results based on chi-square goodness of fit test show that:When the confidence level is respectively $\alpha=0.1$ and $\alpha=0.05$ and the null 
hypothesis that LR statistics subject to $\chi^{2}(1)$ is accepted, $\mathrm{P}$ values are significantly higher than the confidence level. Therefore, the null hypothesis is accepted, and it is believed that the probability of "collision sequence" predicted by $\mathrm{VaR}$ is similar to the confidence level.And with the improvement of the confidence level, the corresponding minimum risk value is larger, which is close to the actual situation, that is, the higher the risk probability that commercial Banks can bear, the higher the risk value is.

\subsection{0ptimal selection of green credit portfolio}

In order to test the effectiveness of this model, this paper respectively uses historical simulation method and equalweight investment scheme to calculate the green credit risk value $V a R_{G P}$. The comparison of the results of $V a R_{G P}$ calculated by the three methods and the optimal portfolio credit weight is shown in the figure below:

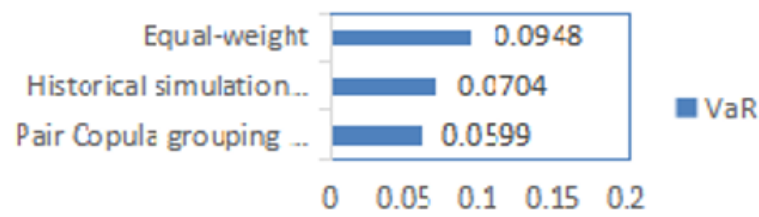

Figure 2.The result of $\mathrm{VaR}_{\mathrm{GP}}$

From the above table, it can be concluded that the credit scheme calculated by Pair Copula grouping -VaR model based on enumeration algorithm can get the minimum $\operatorname{Va} R_{G P}$, that is, the minimum risk faced by commercial Banks.

Therefore, it can be proved that the green credit weight method calculated by Pair Copula grouping -VaR model based on enumeration algorithm has the best effect among the three methods, and it can be considered that this method is feasible in practical operation.

\section{4 conclusion}

This article constructs the green credit risk measurement model of Pair Copula grouping model-VaR method based on the enumeration algorithm, which overcomes the shortcomings of improper and insufficient selection of indicators of analytic hierarchy process and BP neural network proposed by Zhang et al. and Chen et al.,and measures the dependency structure among green financial industries subdivided by business scope and predicts their risks. The following conclusions are drawn:

According to the $\mathrm{R}$ vine structure obtained by the estimated correlation coefficient matrix, it can be concluded that the dependency relationship between atmospheric control and other industries is the largest, followed by environmental monitoring, and the dependency relationship between industrial emission reduction and water treatment is the smallest.At the $95 \%$ confidence level, the minimum risk value that commercial Banks can bear is 0.0599 . At this time, the optimal credit portfolio weight is that industrial emission reduction and water treatment category are the highest, which is respectively 0.4171 and 0.4029 , followed by solid waste treatment category $(0.1104)$, and the air treatment category and environmental monitoring category are the least.

This model is used to evaluate the green credit risk of commercial Banks, optimize the credit portfolio, and obtain the investment plan that commercial Banks should focus green funds on environmental rehabilitation and industrial energy conservation. The investment plan can not only help commercial Banks to make quickly investment decisions according to the industry types of enterprises in the numerous green enterprise application forms, but also maximize the economic benefits of commercial Banks.

\section{Acknowledgements}

This paper is supported by Shandong Natural Science Foundation (ZR201709260010).

\section{Reference}

1. L. He, and L. Liu. "Stand by or Follow? Responsibility Diffusion Effects and Green Credit." Emerging Markets Finance \& Trade (2018).

2. Q. Wang, K. Lai, and D. Niu. "Green Credit Scoring System and Its Risk Assessemt Model with Support Vector Machine." Fourth International Joint Conference on Computational Sciences \& Optimization(2011).

3. Z. Mo, D. Tang, L. Ge. Research on green credit risk management based on KMV model -- Empirical data test from wind power and photovoltaic industry [J]. Management modernization.(2015,35(01):9799).

4. Y. Li , Y. Huang, Y. Wang. Research on credit risk of listed companies in paper industry -- Based on analysis of green factors $[\mathrm{J}]$. Economic problems of forestry.(2018,38(03):46-50).

5. C. Xia. Evaluation and statistical supervision and management of green finance development [J]. Finance and economy.(2018(11):29-35).

6. Sklar A .Functions de repartition a $\mathrm{n}$ dimensions et leursmarges[J]. Publ. Inst. Statistics University Paris.(1959(8):229-231).

7. Z. Chen ,X. Hao. Research on stock market risk optimization based on the cane Copula grouping model $[\mathrm{J}]$. Business economics and manage-ment. (2018(08):89-97).

8. Q. Zhou , Z. Chen, R. Ming . Copula-based grouped risk aggregation under mixed operation[J]. Applications of Mathematics.(2016, 61(1):103-120).

9. Bedford T, Cooke R M. Probability Density Decomposition for Conditionally Dependent Random Variables Modeled by Vines.[J]. Annals of Mathematics \& Artificial Intelligence.(2001, 32(14):245-268). 